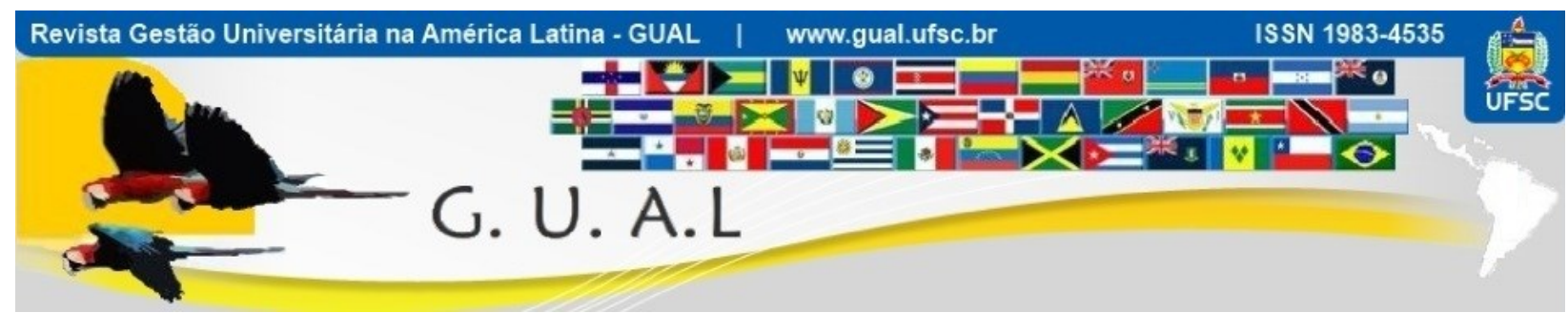

DOI: https://doi.org/10.5007/1983-4535.2021.e74526

\title{
CARACTERÍSTICAS DO CONTROLE INTERNO NAS UNIVERSIDADES FEDERAIS BRASILEIRAS
}

\section{CHARACTERISTICS OF INTERNAL CONTROL IN BRAZILIAN FEDERAL UNIVERSITIES}

\author{
Monike Silva Melo, Mestre \\ https://orcid.org/0000-0002-5927-7851 \\ monike_melo@hotmail.com \\ Universidade Federal de Pernambuco | Centro Acadêmico do Agreste \\ Caruaru | Pernambuco | Brasil
}

Carla Renata Silva Leitão, Doutora https://orcid.org/0000-0001-5175-8901 carlaleitao_ufrpe@yahoo.com.br Universidade Federal Rural de Pernambuco | Programa de Pós-Graduação em Controladoria Recife | Pernambuco | Brasil

Recebido em 04/junho/2020

Aprovado em 26/novembro/2020

Publicado em 01/janeiro/2021

Sistema de Avaliação: Double Blind Review

Esta obra está sob uma Licença Creative Commons Atribuição-Uso. 


\title{
RESUMO
}

$\mathrm{O}$ artigo tem como objetivo investigar as características do controle interno nas Universidades Federais Brasileiras. $\mathrm{O}$ controle interno nas universidades torna-se importante por este ser uma ferramenta essencial para a transparência dos atos públicos, sendo importante ainda para assegurar o patrimônio público e garantir a eficiência na consecução dos objetivos. Sobre a metodologia, a pesquisa apresenta-se como descritiva, e envolveu o uso de questionário como instrumento de coleta de dados. O universo do estudo foi composto pelas 63 Universidades Federais do Brasil listadas na Sinopse Estatística da Educação Superior 2017 do Instituto Nacional de Estudos e Pesquisas Educacionais Anísio Teixeira (INEP). A pesquisa foi realizada de forma censitária obtendo-se resposta de 43 universidades. Foi verificado que $55,8 \%$ das universidades não atribuem a responsabilidade do controle a um setor específico e que um reflexo da não existência de um órgão central responsável pelo controle interno é a pulverização de responsáveis pela elaboração dos controles internos nas instituições. Observou-se ainda que em 13 universidades não existe sequer essa responsabilidade, apesar de apenas 4 das 43 universidades considerarem os controles internos pouco importantes. Assim, pôde-se constatar que apesar da importância atribuída ao controle interno, este ainda não encontra-se consolidado em todas as universidades.

Palavras-chave: Gestão Pública. Controle Interno. Universidades Públicas.

\begin{abstract}
The article aims to investigate the characteristics of internal control in Brazilian Federal Universities. Internal control in universities is important because it is an essential tool for the transparency of public acts and it is also important to ensure public assets and efficiency in achieving the objectives. Regarding the methodology, the research is presented as descriptive, and involved the use of a questionnaire as an instrument of data collection. The study universe consisted of the 63 Federal Universities of Brazil listed in the Statistical Synopsis of Higher Education 2017 of the National Institute of Educational Studies and Research Anísio Teixeira (INEP). The survey was carried out in a census form, obtaining a response from 43 universities. It was found that $55.8 \%$ of universities do not attribute control responsibility to a specific sector and that a reflection of the non-existence of a central body responsible for internal control is the dispersion of those responsible for the elaboration of internal controls in the institutions. It was also observed that in 13 universities there is not even this responsibility, although only 4 of the 43 universities consider internal controls to be unimportant. Thus, it could be seen that despite the importance attributed to internal control, it is not yet consolidated in all universities.
\end{abstract}

Keywords: Public Management. Internal Control. Public Universities. 


\section{INTRODUÇÃO}

O valor do controle interno tem se mostrado como algo crescente com o passar do tempo. Atribui-se a esse crescimento o aumento da demanda por informações dos gestores transformando o controle interno num veículo mais estratégico e gerencial. A estrutura do controle interno deve atender às necessidades societárias, suporte a desempenho e avaliações empresariais (PEREIRA, 2004).

Entende-se que o estudo dos controles internos é relevante, tendo em vista que envolve todos os processos e rotinas, de natureza contábil e administrativa, com o intuito de organizar a entidade de tal maneira que seus colaboradores compreendam, respeitem e façam cumprir as políticas traçadas pela administração, bem como que os ativos tenham sua integridade protegida. E, por fim, que as operações da empresa sejam adequadamente registradas na contabilidade e fidedignamente representadas pelas demonstrações financeiras (MAIA et al., 2005).

Ao direcionar o foco para a administração pública, verifica-se que seus controles internos executam ações que podem ser conduzidas atendendo a normativos legais ou como ferramenta destinada para melhoraria dos níveis de controle administrativos. Em contrário, a não obediência aos normativos e às regras internas com abrangência de todas as áreas da gestão e todas as suas atividades, as entidades tornam-se vulneráveis à ocorrência de fraudes (ARAÚJO et al., 2016).

No Brasil, a lei $\mathrm{n}^{\mathrm{o}}$ 13.303/2016 versa sobre a obrigatoriedade de implementar e supervisionar práticas cotidianas dos sistemas de gestão de riscos e de controle interno estabelecidos para a prevenção e contenção dos principais riscos a que está exposta a empresa pública ou a sociedade de economia mista, inclusive os riscos relacionados à integridade das informações contábeis e financeiras e os relacionados à ocorrência de corrupção e fraude (BRASIL, 2016).

$\mathrm{Na}$ administração pública, a necessidade e obrigatoriedade da adoção do controle interno administrativo é desempenhado pelo executivo e pelos órgãos de administração dos demais poderes relativos a sua própria atividade. Esse controle tem por objetivo manter nessas atividades a devida adequação aos preceitos legais, sempre respeitando as exigências dos serviços e as necessidades técnicas de sua realização, assumindo três aspectos para essa operacionalização: controle de legalidade, de conveniência e de eficiência (THOMÉ; TINÔCO, 2005). 
No entanto, é importante ultrapassar a barreira do controle interno apenas como órgão com foco apenas em confrontar e fiscalizar por meio de acompanhamento às atividades, metas e objetivos, comparando o planejado com o executado, a eficiência, eficácia e efetividade na aplicação dos recursos e na consecução dos serviços destinados à sociedade. É necessário que estes controles internos sejam capazes de avaliar e responder a riscos intrínsecos. Para tanto, faz-se necessária a existência de uma central de sistema de controle interno, responsável pela implantação de rotinas e procedimentos para as práticas de controle interno que garantam a execução desses acompanhamentos, fiscalização e controles em todas as unidades do ente ao qual pertence.

Destaca-se que existem muitos desafios da gestão pública na busca de maneiras e soluções para gerir recursos públicos e ao mesmo tempo oferecer serviços de qualidade à população. O administrador tem como desassociar o controle interno de suas ações e o resultado disto é resguardar os recursos públicos contra os erros, as fraudes, os desperdícios e as irregularidades (MORAES; OLIVEIRA; NIWA, 2013).

Um exemplo do papel desempenhado pelas instituições públicas, bem como da importância do sistema de controle, consiste na atuação das Universidades Públicas Federais que ultrapassa a barreira do desenvolvimento de conhecimento científico, cultural e tecnológico. Por prestar serviços à sociedade com uso de recursos públicos, elas têm a obrigação de se manterem atentas e dispostas ao desenvolvimento e aprimoramento contínuo de sua gestão. Assim, um controle interno ativo e abrangente é o órgão capaz de propiciar de forma eficiente e eficaz esse atingimento. $\mathrm{O}$ uso do controle interno como suporte à gestão universitária, com base em um sistema de informação e avaliação eficiente, será capaz de resguardar o patrimônio e os recursos públicos, por meio da detecção de fraudes, desvios e avaliação da gestão quanto ao cumprimento de metas e à execução de orçamentos, no tocante aos aspectos de economicidade, eficiência, eficácia e efetividade (QUEIROZ et al., 2012).

Desse entendimento, surge a importância do estudo do controle interno no âmbito das universidades públicas, tendo em vista que é por meio desse controle que se pode garantir o uso dos recursos públicos em sua plenitude e proporcionar maior transparência dos atos praticados, logo, fica claro que a identificação das práticas de controles internos adotadas pelas universidades federais brasileiras é de interesse primordial da sociedade que é seu principal stakeholder.

Assim, o artigo tem como objetivo investigar as características do controle interno nas Universidades Federais Brasileiras. 


\section{REFERENCIAL TEÓRICO}

\subsection{CONTROLE INTERNO}

O controle interno tem sido descrito como um processo composto de práticas, técnicas e rotinas para auxiliar na proteção dos ativos e da integridade dos registros contábeis da organização, bem como fomentar eficientemente operações eficazes e em conformidade com regulamentos. O termo "controles" refere-se a qualquer aspecto dos componentes do controle interno. Logo, o controle interno é alicerçado por processos técnicos, como reconciliação de contas, comparação de metas orçadas com executadas, separação de funções incompatíveis, autorização apropriada de funções (WANG; HOOPER, 2017).

O instituto de Auditores Internos do Brasil (IIA) registra que controles internos devem ser entendidos como qualquer ação tomada pela administração (assim compreendida tanto a alta administração como os níveis gerenciais apropriados) para aumentar a probabilidade de que os objetivos e metas estabelecidos sejam atingidos (IIA, 1992, p.48, apud MAIA et al. 2005). Wang e Hooper (2017) corroboram esse entendimento quando afirmam que o controle interno efetivo é mais do que apenas um processo, deve possuir uma gama mais ampla de aspectos fundamentais relacionados à maneira como uma organização opera.

Silva (2002), ao delinear essa temática, explana que o controle interno é um conjunto de ações e medidas por meio do qual uma organização controla suas atividades, com vistas à salvaguarda do patrimônio, exatidão e fidedignidade das informações contábeis, e eficiência operacional, como meios para alcançar os objetivos globais da organização.

Diante desses conceitos, pode-se afirmar que controle interno envolve todas os processos e rotinas, de natureza contábil e administrativa, com o intuito de organizar a entidade de tal maneira que seus colaboradores compreendem, respeitam e façam cumprir as políticas traçadas pela administração, bem como os ativos tenham sua integridade protegida. E por fim, que as operações da organização sejam adequadamente registradas na contabilidade e fidedignamente pelas demonstrações financeiras (MAIA et al., 2005).

Calixto e Velásquez (2005) enfatizam o conceito de controle interno enquanto uma ferramenta de gestão. Para os autores o controle interno é composto pela junção da estrutura organizacional somado aos mecanismos de controle estabelecidos pela gestão, atribuído ainda normas internas que estabeleçam as responsabilidades das atividades, rotinas de trabalho, técnicas de revisão de ações, concordância e registro das operações. Neste sentido o 
planejamento da organização das ações precisa antever uma separação adequada das responsabilidades de cada função.

Nesse aspecto, o controle interno pode ser utilizado, como sugestão de metas e objetivos planejados pela instituição, esta importância se torna evidente quando fica impossível idealizar uma entidade que não disponha de controles que possam garantir a continuidade do fluxo de operações e informações planejadas (LORENZONI; VIEIRA, 2013).

O uso do controle interno pela organização deve ser visto como uma ferramenta que apoie o desenvolvimento de suas ações, que suportem a administração para o atingimento das metas e objetivos sempre pautando suas atividades em obediência aos normativos. Ayres et al. (2018) defendem ainda que o referido controle tem por missão a adaptação ao tamanho da organização, sendo primordial ações que atendam em tempo hábil os anseios da entidade, e que, seus custos não sejam superiores aos benefícios.

Monteiro (2015) afirma que o sistema de controle interno é de extrema relevância para o acompanhamento dos atos da administração da entidade, levando em consideração suas atribuições não só no campo de controle de responsabilidades, mas também com a sua preocupação em salvaguardar, examinar, acompanhar o desempenho através de controles apropriados. É importante a não limitação do uso do controle interno apenas para evitar erros ou práticas fraudulentas.

Por sua vez, Pereira (2004) observa que os papéis exercidos pelo controle interno são diversos, e que de acordo com a literatura seu foco principal é o de disponibilizar informação para a administração. Entende-se que a informação segura e tempestiva contemplará diversas necessidades empresariais e de difícil separação dos atos gerenciais, como: recolher tributos, tributos, promover evidenciação contábil, salvaguardar os ativos, dessa forma é possível identificar vários objetivos do controle interno destacando-se a informativa dando suporte ao processo decisório.

O entendimento das mudanças ao longo do tempo ocorridas nos conceitos de controle internos é de suma importância, ele evoluiu de um simples procedimento de controle para uma estruturação adequada de controles internos. Essa estruturação pode ser definida como processos executados para fornecer uma segurança razoável com relação ao cumprimento dos objetivos da instituição, à eficiência e eficácia nas operações, a integridade dos relatórios financeiros e a aderência às leis e normas aplicáveis (RITTA, 2010). 
O controle interno possui diversas finalidades que justificam sua existência, para Castro (2010) cinco delas merecem um destaque especial. A primeira delas refere-se a segurança do ato praticado e obtenção de informação adequada, a cautela é a chave para que os atos cometidos estejam de acordo com a legislação e que quando sujeitos a julgamentos externos estejam suportados por controles internos prévios e seguros. As informações suportadas pelos controles referem-se tanto ao ato em si como ao resultado proveniente dele, por esta razão para o administrador que responde pelo que decide é que o controle interno prévio trará segurança.

O controle interno pode ser dividido em controles administrativos e controles contábeis. Referente aos controles administrativos há o entendimento de que eles abrangem o plano de organização e todos os métodos e procedimentos referentes à eficiência operacional e à obediência às diretrizes administrativas, que normalmente, se relacionam apenas de forma indireta com os registros contábeis. Compreendem controles que objetivam verificação física, controle de contratos, convênios, ações desenvolvidas, retenções e recolhimento de tributos. Relacionado aos controles contábeis abarcam o plano de organização e todos os procedimentos diretamente relacionados com a consistência, a fidedignidade e a veracidade dos registros contábeis. Envolvem também controles que dão sustentação aos números apresentados nos demonstrativos elaborados pela área contábil, como os sistemas que dão suporte aos atos praticados (AICPA, 1958 apud CASTRO, 2010).

As limitações inerentes ao controle interno caracterizam-se como as de que o custo do controle interno não exceda os benefícios a serem obtidos; de que o foco dos controles internos tende a ser direcionado para transações rotineiras invés de para todas as transações; a possibilidade de erro humano em função de distração, erros de julgamento e instruções malentendidas; a não identificação das fraquezas dos controles internos que permitem contornalos por meio de conluio de um membro da administração ou empregado com partes de fora (terceiros) ou de dentro da entidade; o não impedimento de abuso de poder por meio de pessoa responsável por exercer um controle interno, como exemplo um membro da administração que passe por cima de um controle interno; e por fim a possibilidade de que procedimentos se tornem obsoletos e inadequados devido a mudanças nas condições e de que o cumprimento desses procedimentos se deteriore (RITTA, 2010). 


\subsection{CONTROLE INTERNO NA GESTÃO PÚBLICA}

Para Chiarelli e Cherobim (2009, p. 25), “O controle é uma das funções clássicas da administração de qualquer entidade, seja pública ou privada, sendo precedido pelas atividades administrativas de planejamento, organização e coordenação". As autoras afirmam que na administração pública o controle assume uma importância e abrangência ainda maior, visto que essa é uma obrigação legal por meio da obrigatoriedade de prestação de contas a que todo ente governamental está submetido.

Calixto e Velasquez (2005) relatam que a história do controle interno na Administração Pública Federal do Brasil teve seu marco inicial na Lei n. 4.320/64, responsável pela introdução das expressões controle interno e controle externo, a qual apresentou a definição para as competências do exercício daquelas atividades. Esta Lei atribuiu ao Poder Executivo o controle interno, enquanto o controle externo foi atribuído ao Poder Legislativo.

Observa-se a partir daí que o controle interno na administração pública se desenvolveu principalmente atrelado ao conceito de controle de gestão financeira, mudando para uma pespectiva mais ampla após a Constituição Federal de 1988.

A gestão pública tem passado por uma escassez de recursos e isso impulsiona o aumento do interesse em governar de forma eficiente e eficaz os recursos públicos objetivando atender plenamente as necessidades da sociedade. No contexto atual da administração pública que cada vez mais se exige a eficiência da gestão, mas em contrapartida é estigmatizada pela falta de recursos, é observado um reflexo no comportamento dos administradores públicos de elevada preocupação nos aspectos que tangem à existência de um controle mais eficiente nas entidades cuja administração é de sua responsabilidade (CALIXTO; VELÁSQUEZ, 2005). Assim, com o objetivo de superar essas limitações as entidades públicas têm buscado a instrumentalização de sua gestão com sistemas de controle interno que subsidiam o controle externo e garantem a obediência imposta pela legislação exercendo controles de forma preventiva e concomitante aos atos administrativos (CALIXTO; VELÁSQUEZ, 2005).

A literatura apresenta diversos objetivos para o controle interno na administração pública e em sua grande parte há a caracterização de proteção do interesse público, proteção do bem público e suporte à gestão. $\mathrm{O}$ controle interno penetra em toda a organização para detectar possíveis falhas, desvios ou deficiências, objetivando através de suas informações conduzir a 
administração a efetuar mudanças no curso da ação e possíveis modificações de políticas administrativas caso seja necessário. Complementa ainda afirmando que ao controle interno compete prestar informações de maneira permanente à administração superior sobre todas as áreas relacionadas com controle seja contábil, administrativo, operacional ou jurídico, bem como colocar como prioridade os interesses da organização contra ilegalidades, erros ou outras irregularidades garantindo a consecução de metas pretendidas e recomendando quando necessário ajuste com vistas à eficiência operacional (OLIVEIRA, 2014).

Monteiro (2015) apresenta uma lista contendo onze objetivos do controle interno no setor público, que são: a proteção de ativos; a obtenção de informações apropriadas; apoio à eficiência operacional; potencialização do êxito do processo decisório; indução do comportamento focado no resultado; garantia do respeito a normas e regulamentos da entidade (comportamento ético); comprovação da veracidade de informações contábeis e financeiras e operacionais; exercício do controle das operações de crédito, avais e garantias, bem como dos direitos e haveres dos órgãos públicos; apoio ao controle externo no exercício de sua missão institucional; apoio e controle da responsabilidade na gestão fiscal, conforme a LRF; e zelo pelo cumprimento das obrigações e prestação de contas.

Alguns estudos tem sido conduzidos sobre o controle interno no âmbito público, os quais podem ser visualizados na Tabela 1 .

Tabela 1 Estudos anteriores relacionados

\begin{tabular}{l|l|l}
\hline \multicolumn{1}{c|}{ Autor } & \multicolumn{1}{c}{ Título } & \multicolumn{1}{c}{ Objetivo } \\
\hline Oliveira (2006) & $\begin{array}{l}\text { Contabilidade, controle interno } \\
\text { e controle externo: trinômio } \\
\text { necessário para combater a } \\
\text { corrupção. }\end{array}$ & $\begin{array}{l}\text { Discutir como os sistemas de controle } \\
\text { governamentais, definidos como sistemas de } \\
\text { contabilidade, de controle interno e de controle } \\
\text { externo, podem ser instrumentos de combate à } \\
\text { corrupção. }\end{array}$ \\
\hline $\begin{array}{l}\text { Calixto e } \\
\text { Velasquez (2005) }\end{array}$ & $\begin{array}{l}\text { Sistema de controle interno na } \\
\text { administração Pública federal. }\end{array}$ & $\begin{array}{l}\text { Identificar se o Sistema de Controle Interno } \\
\text { contribui para que haja uma eficiente execução das } \\
\text { propostas de governo, diminuindo os riscos } \\
\text { inerentes ao desvio de recursos e/ou a aplicação } \\
\text { irregular de dinheiro público. }\end{array}$ \\
\hline $\begin{array}{l}\text { Thomé e Tinoco } \\
\text { (2005). }\end{array}$ & $\begin{array}{l}\text { A existência do controle } \\
\text { interno como auxílio à } \\
\text { governança para gerar } \\
\text { informações aos stakeholders } \\
\text { das entidades Públicas: a } \\
\text { realidade em 20 prefeituras do } \\
\text { estado do Paraná - Brasil. }\end{array}$ & $\begin{array}{l}\text { Verificar a efetividade do uso do controle interno em } \\
\text { vinte prefeituras, localizadas no Estado do Paraná. }\end{array}$ \\
$\begin{array}{l}\text { A influência da lei de } \\
\text { responsabilidade fiscal nos } \\
\text { procedimentos de controle } \\
\text { interno: uma análise nos } \\
\text { Municípios gaúchos do Corede }\end{array}$ & $\begin{array}{l}\text { Avaliar a estruturação de procedimentos nas áreas } \\
\text { de orçamento, contabilidade, patrimônio e } \\
\text { estruturação do controle interno nos municípios } \\
\text { gaúchos do respectivo Corede, com a finalidade de } \\
\text { identificar as principais mudanças ocorridas na }\end{array}$ \\
\hline
\end{tabular}




\begin{tabular}{|c|c|c|}
\hline Autor & Título & Objetivo \\
\hline & Produção. & gestão municipal no período posterior à lei. \\
\hline $\begin{array}{l}\text { Conti e Carvalho } \\
\text { (2011) }\end{array}$ & $\begin{array}{l}\text { Controle Interno na } \\
\text { Administração Pública } \\
\text { Brasileira: Qualidade do Gasto } \\
\text { Público e Responsabilidade } \\
\text { Fiscal. }\end{array}$ & $\begin{array}{l}\text { Analisar aspectos relacionados ao controle interno } \\
\text { na Administração Pública brasileira. }\end{array}$ \\
\hline $\begin{array}{l}\text { Albuquerque } \\
(2011)\end{array}$ & $\begin{array}{l}\text { Avaliação dos controles } \\
\text { internos de uma instituição } \\
\text { pública de ensino superior à luz } \\
\text { da metodologia MCDA - } \\
\text { construtivista. }\end{array}$ & $\begin{array}{l}\text { Construir um modelo de avaliação dos controles } \\
\text { internos de uma Instituição Pública de Ensino } \\
\text { Superior por meio da Multicritério de Apoio à } \\
\text { Decisão-Construtivista (MCDA-C), que permita } \\
\text { implementar um sistema de controle eficaz por parte } \\
\text { dos gestores, em prol da missão institucional da } \\
\text { Instituição Pública de Ensino Superior. }\end{array}$ \\
\hline $\begin{array}{l}\text { Vasconcelos et al. } \\
\text { (2012) }\end{array}$ & $\begin{array}{l}\text { Funcionalidade Do Controle } \\
\text { Interno Nos Municípios: Um } \\
\text { Estudo nas Prefeituras de Uma } \\
\text { Região Metropolitana do } \\
\text { Nordeste Brasileiro. }\end{array}$ & $\begin{array}{l}\text { Analisar como vem sendo desenvolvido o Controle } \\
\text { Interno nas prefeituras da região metropolitana de } \\
\text { Natal no Rio Grande do Norte. }\end{array}$ \\
\hline $\begin{array}{l}\text { Soares e Scarpin } \\
\text { (2013) }\end{array}$ & $\begin{array}{l}\text { Controle Interno na } \\
\text { Administração Pública: } \\
\text { avaliando sua eficiência na } \\
\text { gestão municipal. }\end{array}$ & $\begin{array}{l}\text { Avaliar, a partir dos controles orçamentários e } \\
\text { financeiros praticados, o grau de eficiência dos } \\
\text { controles internos dos municípios que compõem a } \\
\text { região da Associação dos Municípios do Médio Vale } \\
\text { do Itajaí - AMMVI, estado de Santa Catarina. }\end{array}$ \\
\hline Monteiro (2015) & $\begin{array}{l}\text { Análise do sistema de controle } \\
\text { interno no Brasil: objetivos, } \\
\text { importância e barreiras para } \\
\text { sua implantação. }\end{array}$ & $\begin{array}{l}\text { Realizar uma análise das finalidades e importância } \\
\text { do sistema de controle interno na administração } \\
\text { pública do Brasil e das barreiras para sua } \\
\text { implantação. }\end{array}$ \\
\hline
\end{tabular}

Fonte: Dados da pesquisa (2019)

No entanto, apesar de pesquisas estarem sendo conduzidas no âmbito público, observou-se uma escassez de estudos no âmbito das universidades públicas, especificamente as Federais, o que apresentou-se como uma das motivações para a presente pesquisa.

\section{METODOLOGIA}

A pesquisa é caracterizada como descritiva tendo em vista que serão registrados e descritos os fatos observados sem interferência neles, como estabelecem Prodanov e Freitas (2013) e Gil (2002). Em relação à abordagem, o método utilizado foi o quantitativo.

Sobre o universo da pesquisa, Este foi formado pelas 63 unversidades federais listadas na Sinopse Estatística da Educação Superior 2017, do Instituto Nacional de Estudos e Pesquisas Educacionais Anísio Teixeira (INEP). A pesquisa foi realizada de forma censitária, a qual, de acordo com Gil (2002, p. 51), ocorre "quando o levantamento recolhe informações de todos os integrantes do universo pesquisado, tem-se um censo".

Por se tratar de pesquisa censitária, os questionários foram enviados por correio eletrônico para todas as universidades integrantes do universo, obtendo-se o retorno de 48 universidades do total de 63 universidades. Das respostas obtidas, 3 universidades enviaram 
em duplicidade e 2 universidades não responderam as questões abertas de forma compreensível, por essa razão 5 questionários foram descartados, o que perfez o número de 43 questionários aptos a compor a pesquisa.

Para atendimento dos objetivos, foi utilizada estatística descritiva dos dados coletados para descrever os fatos e características por meio da organização e sumarização dos números (STEVENSON, 1981). De acordo com o objetivo do estudo, por meio da análise da população, e partir dessa análise, foi possível determinar as características que a compõe. A estatística descritiva deu suporte a uma esquematização de forma resumida e organizada aos dados coletados.

\section{RESULTADOS}

Inicialmente buscou-se caracterizar o perfil dos respondentes. Os resultados revelaram que dos 43 respondentes 29 eram do sexo masculino, o que representa em termos percentuais 67,4\%. A maior parte dos respondentes possuia especialização, representado por 23 respondentes, que em termos percentuais totaliza 53,5\%, 12 possuiam o título de mestre e 5 de doutor, representando respectivamente $27,9 \%$ e $11,6 \%$ dos participantes. Sobre a formação do respondente o curso de ciências contábeis foi o mais citado, totalizando 19 respondentes e um valor percentual de 44,2\%; em segundo lugar ficou o curso de direito com um total de 16 e um valor percentual de $37,2 \%$. Ainda foram citados os cursos de economia $(4,7 \%)$ e administração (4,7\%), além de outros cursos (os quais totalizaram 9,2\%) .

Sobre a faixa etária dos respondentes, o maior número de respondentes transitou na faixa de 41 a 40 anos o que apresentou um total de 21 respondentes e um percentual de 48,8\%. Nas faixas etárias de 41 a 50 anos e acima de 50 anos somaram 19 respondentes e isso representa em termos percentuais um total de 44,2\%. A faixa etária com menos representatividade foi a abaixo de 30 anos com um total de 3 respondentes e uma representatividade de apenas $7 \%$.

Sobre o departamento de lotação do respondente a grande maioria dos respondentes estava lotado na auditoria interna, o que representa um total de 38 e em termos percentuais $88,4 \%$. Em segundo lugar apareceu o gabinete do reitor, com um total de 3 respondentes (o que representou $7 \%$ dos respondentes) e apenas 1 respondente estava lotado na controladoria interna e 1 na Pró-reitoria de Planejamento e Orçamento o que representou 2,3\% cada.

O maior número de respostas obtidas foi da região nordeste, com um total de 16 universidades e uma representatividade percentual de $37,2 \%$. O Sudeste foi a segunda região 
com o maior número de universidades com um total de 9 , o que representou $20,9 \%$. O Norte apresentou 8, o Sul 7 e o Centro-Oeste 3 representando respectivamente em termos percentuais $18,6 \%, 16,3 \%$ e $7 \%$.

Em seguida, buscou-se observar a existência de órgãos de controle interno, a sua estrutura na organização e a importância atribuída pela gestão.

A Tabela 2 apresenta a existência em sua estrutura organizacional da universidade de um órgão ou setor responsável pelo controle interno. De acordo com Calixto e Velásquez (2005), o controle interno é composto pela junção da estrutura organizacional somado aos mecanismos de controle estabelecidos pela gestão. Como pode ser observado, 24 das universidades respondentes não possuem órgão de controle interno em sua estrutura organizacional o que representa $55,8 \%$. Das universidades participantes do estudo $44,2 \%$ tem em sua estrutura organizacional um órgão ou setor de controle interno instituído o que representa 19 universidades.

Tabela 2 Existência na estrutura organizacional de um órgão ou setor responsável pelo controle interno.

\begin{tabular}{c|c|c}
\hline & Frequência & Frequência relativa (\%) \\
\hline Sim & 19 & 44,2 \\
\hline Não & 24 & 55,8 \\
\hline Total & 43 & 100 \\
\hline
\end{tabular}

Fonte: Dados da pesquisa (2019).

Em seguida foi perguntado a quem o órgão de controle interno estva subordinado. Esta questão foi direcionada apenas às 19 universidades que haviam respondido sim à questão anterior. O maior número está subordinado ao Conselho Universitário, o que representa $31,5 \%$ e um total de 6 universidades (Tabela 3). Ao gabinete do reitor está subordinado, 5 o que representa 26,3\%. As demais subordinações estão representadas por mais 6 órgãos das universidades. Essa pulverização nas respostas é convergente aos apontamentos de Rezende e Favero (2004). Segundo os autores a quem este órgão está subordinado não é determinante tendo em vista que todos estão aptos a melhorar e aprimorar os controles internos.

Para aqueles que responderam não à existência do controle interno na estrutura organizacional, foi perguntado se existia um setor/órgão/departamento responsável pelos controles interno. Como resposta, das 24 universidades que não possuíam em sua estrutura organizacional esse setor instituído, a maioria $(54,17 \%)$ respondeu que não existia esse setor; o que representa 13 respondentes. Sete universidades afirmaram que cada setor é responsável pela instituição dos controles internos, o que representa $29,17 \%$ dos respondentes, 2 
universidades atribuíram essa responsabilidade á Pró-reitoria de Planejamento, 1 universidade ao Comitê de governança, riscos e controles internos e por fim 1 a Auditoria Interna. Os resultados dessa questão encontram-se evidenciados na Tabela 4.

Tabela 3 Subordinação do órgão responsável pelo controle interno

\begin{tabular}{l|c|c}
\hline & Frequência & Frequência relativa (\%) \\
\hline Conselho universitário & 6 & 31,5 \\
\hline Gabinete do reitor & 5 & 26,3 \\
\hline Pró-reitora de planejamento & 2 & 10,5 \\
\hline Conselho superior & 1 & 5,3 \\
\hline Conselho diretor & 1 & 5,3 \\
\hline Comitê de Governança, Gestão de Riscos e Controles Internos & 1 & 5,3 \\
\hline Conselho de administração & 2 & 10,5 \\
\hline Coordenação de controle interno & 1 & 5,3 \\
\hline Total & 19 & 100 \\
\hline
\end{tabular}

Fonte: Dados da pesquisa (2019).

Sobre esse aspecto, o fato de não existir um setor nomeadamente de controle interno não se apresenta como um potencial problema. Pois, conforme as considerações de Rezende e Favero (2004), independente do setor ou cargo declarado como responsável pelos controles internos, todos são considerados capazes para o correto funcionamento e aptos no desenvolvimento de atividades que possam melhorar à sua qualidade.

Tabela 4 Setor/Órgão/Departamento/ responsável pelos controles internos

\begin{tabular}{l|c|c}
\hline & Frequência & Frequência relativa (\%) \\
\hline Não existe & 13 & 54,17 \\
\hline Cada setor/departamento & 7 & 29,17 \\
\hline Pró-reitoria de planejamento & 2 & 8,34 \\
\hline Comitê de governança, riscos e controles internos & 1 & 4,16 \\
\hline Auditoria Interna & 1 & 4,16 \\
\hline Total & 24 & 100 \\
\hline
\end{tabular}

Fonte: Dados da pesquisa (2019).

A questão seguinte indagava se a universidade possuia controles internos instituídos. Como apresentado na Tabela 5, a maioria das universidades $(51,2 \%)$ possui controles internos instituídos e formalizados, enquanto 17 possuem controles instituídos, mas não formalizados o que representa $39,5 \%$ das universidades que fazem parte do estudo. Apenas 4 universidades afirmaram não possuir controles internos instituídos o que representa 9,3\%.

A próxima questão versava sobre a avaliação do sistema de controle. Nesse aspecto, destaca-se que é de extrema importância a avaliação do controle interno, a qual deve ser feita primeiramente para a determinação da natureza, da profundidade e da extensão dos exames 
finais e em seguida sugerir aprimoramento em relatório específico (PINTO, 2006). Os dados convergem nesse sentido, visto que sobre a importância atribuída à avaliação do sistema de controles interno das universidades observou-se, conforme aponta a Tabela 6, que 20 universidades afirmaram que é extremamente importante a avaliação, o que representou 46,5\%. Dez universidades $(23,3 \%)$ consideraram muito importante essa avaliação. Nove universidades $(20,9 \%)$ consideraram importante e 4 universidades $(9,3 \%)$ declararam que consideram pouco importante a avaliação do sistema de controle interno da universidade.

Tabela 5 Instituição dos controles internos

\begin{tabular}{l|c|c}
\hline & Frequência & Frequência relativa (\%) \\
\hline Sim, formalizados & 22 & 51,2 \\
\hline Sim, mas não formalizados & 17 & 39,5 \\
\hline Não & 4 & 9,3 \\
\hline Total & 43 & 100 \\
\hline
\end{tabular}

Fonte: Dados da pesquisa (2019).

Tabela 6 Importância atribuída à realização de avaliações do sistema de controle interno

\begin{tabular}{l|c|c}
\hline & Frequência & Frequência relativa (\%) \\
\hline Nenhuma importância & 0 & 0 \\
\hline Pouco importante & 4 & 9,3 \\
\hline Importante & 9 & 20,9 \\
\hline Muito importante & 10 & 23,3 \\
\hline Extremamente importante & 20 & 46,5 \\
\hline Total & 43 & 100 \\
\hline
\end{tabular}

Fonte: Dados da pesquisa (2019).

Após a apresentação do resultado sobre a importância atribuída à realização de avaliações do sistema de controle interno foi realizado um cruzamento de dados para verificar se a formação do respondente impactava nas respostas. Os resultados não apresentam discrepâncias relacionadas a formação dos respondentes, conforme é possível observar na Tabela 7.

Complementando a pergunta anterior, indagou-se se eram realizadas avaliações periódicas do sistema de controle interno pela universidade e se há periodicidade nessa avaliação. Como resposta, 15 universidades afirmaram que fazem avaliação e que esta ocorre com periodicidade determinada, o que representou 34,9\%. Em 23 universidades observou-se a afirmação de que fazem a avaliação, mas que não há periodicidade; e 5 universidades afirmaram que não fazem avaliação do sistema de controle interno, o que representou 11,6\% das universidades em estudo, conforme Tabela 8. 
Tabela 7 Cruzamento dos resultados da formação dos respondentes com a importância atribuída às avaliações do sistema de controle interno

\begin{tabular}{|c|c|c|c|c|c|c|}
\hline & & \multicolumn{4}{|c|}{$\begin{array}{c}\text { Importância atribuída à realização de avaliações do } \\
\text { sistema de controle interno }\end{array}$} & \multirow{2}{*}{ Total } \\
\hline & & $\begin{array}{c}\text { Pouca } \\
\text { importância }\end{array}$ & Importante & \begin{tabular}{c|} 
Muito \\
importante
\end{tabular} & $\begin{array}{c}\text { Extremamente } \\
\text { importante }\end{array}$ & \\
\hline \multirow{9}{*}{ Formação } & Administração & 0 & 0 & 1 & 1 & 2 \\
\hline & $\begin{array}{l}\text { Ciências } \\
\text { Contábeis }\end{array}$ & 1 & 4 & 4 & 10 & 19 \\
\hline & Economia & 1 & 0 & 0 & 1 & 2 \\
\hline & Direito & 1 & 5 & 4 & 5 & 15 \\
\hline & Informática & 0 & 0 & 0 & 1 & 1 \\
\hline & $\begin{array}{l}\text { Ciências } \\
\text { Sociais }\end{array}$ & 0 & 0 & 0 & 1 & 1 \\
\hline & História & 0 & 0 & 0 & 1 & 1 \\
\hline & Gestão Pública & 1 & 0 & 0 & 0 & 1 \\
\hline & Letras & 0 & 0 & 1 & 0 & 1 \\
\hline \multicolumn{2}{|l|}{ Total } & 4 & 9 & 10 & 20 & 43 \\
\hline
\end{tabular}

Fonte: Dados da pesquisa (2019).

Tabela 8 Realização de avaliações do sistema de controle interno da universidade

\begin{tabular}{l|c|c}
\hline & Frequência & $\begin{array}{c}\text { Frequência relativa } \\
(\mathbf{\%})\end{array}$ \\
\hline Sim, a avaliação é realizada periodicamente & 15 & 34,9 \\
\hline Sim, mas não há periodicidade pré-determinada & 23 & 53,5 \\
\hline Não & 5 & 11,6 \\
\hline Total & 43 & 100 \\
\hline
\end{tabular}

Fonte: Dados da pesquisa (2019).

Para as 38 universidades que afirmaram que fazem avaliação dos seus sistemas de controle interno, foi indagado sobre as atividades compreendidas nessa avaliação. Nessa questão era permitida a marcação de mais de uma alternativa.

Para Pinto (2006), a avaliação do controle interno deve seguir uma sequência de ações. A primeira delas é determinar os erros ou irregularidades que podem acontecer, em seguida verificar se o sistema atual de controles detectaria imediatamente tais erros e a partir daí analisar as fraquezas ou falta de controle que permitem a existência desses erros, com a finalidade de determinar a natureza, data e extensão dos procedimentos de auditoria. Por fim, emitir relatório com comentário sugerindo o aprimoramento do sistema de controle interno da empresa.

Quando verificada quais atividades eram compreendidas na avaliação do controle interno das universidades, conforme apresentado na Tabela 9, 18 universidades afirmaram que fazem a determinação da possibilidade de ocorrência de erros e irregularidades. 12 afirmaram que realizam a verificação de se o sistema de controles detectaria de imediato erros e 
irregularidades. 32 afirmaram que fazem análise das fraquezas ou falta de controle que possam contribuir para a ocorrência de erros ou irregularidades e 38 afirmam que avaliam a emissão de relatório com sugestões para o aprimoramento do sistema de controle interno.

Tabela 9 Atividades compreendidas na avaliação do controle interno

\begin{tabular}{l|c|c}
\hline & Frequência & Frequência relativa (\%) \\
\hline $\begin{array}{l}\text { A determinação da possibilidade de ocorrência de erros ou } \\
\text { irregularidades. }\end{array}$ & 18 & 47,38 \\
\hline $\begin{array}{l}\text { A verificação de se o sistema de controles detectaria de } \\
\text { imediato erros ou irregularidades. }\end{array}$ & 12 & 31,58 \\
\hline $\begin{array}{l}\text { A análise das fraquezas ou falta de controle, que possam } \\
\text { contribuir para a ocorrência de erros ou irregularidades. }\end{array}$ & 32 & 84,21 \\
\hline $\begin{array}{l}\text { A emissão de relatório com sugestões para o aprimoramento do } \\
\text { sistema de controle interno }\end{array}$ & 38 & 89,37 \\
\hline
\end{tabular}

Fonte: Dados da pesquisa (2019).

O questionamento seguinte abordava os tipos de controle interno utilizados. Assim como a questão anterior, esta permitia a marcação de mais de uma opção.

De acordo com Thomé e Tinoco (2005), o controle interno deve ser visto como um processo que contempla estrutura organizacional, política de recursos humanos, segregação de funções e ética, entre outros, com o objetivo de proteger a organização de riscos que inviabilizem ou dificultem a sua gestão. Assim, deve-se prever controles para todas as perspectivas desse processo.

Como pode ser observado na Tabela 10, sobre a segregação de funções (separação das funções de aprovação, execução e controle) 41 universidades afirmaram que possuem esse controle, o que representa $95,3 \%$. O segundo tipo mais escolhido foi o sistema de conferência, aprovação e autorização, com 34 universidades afirmando que fazem uso desse controle, o que representa 79,1\%. Quanto a controle físico dos ativos, 33 universidades afirmaram utilizar esse tipo de controle. Constata-se ainda que 37 fazem treinamento de pessoal, 21 fazem análises orçamentárias, 13 controles de erros e fraudes contábeis, 11 controles de qualidade e apenas 3 universidades afirmaram que possuem outros tipos de controle interno.

Vieira et al. (2007) entendem que a definição de procedimentos de controle interno considera as especificidades de cada organização, como estrutura organizacional, complexidade das operações e natureza do negócio. Algumas são essenciais, dentre os quais cabe estudar o controle periódico dos saldos físicos e financeiros e o confronto desses saldos. 
Tabela 10 Tipos de controles internos utilizados

\begin{tabular}{l|c|c}
\hline & Frequência & Frequência relativa (\%) \\
\hline Sistema de conferência, aprovação e autorização & 34 & 79,1 \\
\hline $\begin{array}{l}\text { Segregação de funções (separação das funções de } \\
\text { aprovação, execução e controle) }\end{array}$ & 41 & 95,3 \\
\hline Controle físico sobre os ativos & 33 & 76,7 \\
\hline Controle de qualidade & 11 & 25,6 \\
\hline Treinamento de pessoal & 37 & 86 \\
\hline Análises orçamentárias & 21 & 48,8 \\
\hline Controle de erros e fraudes contábeis & 13 & 30,2 \\
\hline Outro & 3 & 6,9 \\
\hline
\end{tabular}

Fonte: Dados da pesquisa (2019).

Relacionado a essa temática, sobre controle periódico dos saldos físicos e financeiros 26 universidades afirmaram que o fazem e que este é realizado de forma periódica; isso representa um percentual de 60,5\%. Sobre as demais, 30,2\% afirmaram que realizam o controle dos saldos físicos e financeiros, mas que não há periodicidade pré-determinada. Esse percentual é representado por 13 universidades. Apenas 4 universidades afirmaram não realizar esse controle, o que representou em termos percentuais 9,3\%, como pode ser observado na Tabela 11.

Tabela 11 Controle dos saldos físicos e financeiros

\begin{tabular}{l|c|c}
\hline & Frequência & Frequência relativa (\%) \\
\hline Sim, o controle é realizado periodicamente & 26 & 60,5 \\
\hline Sim, mas não há periodicidade pré-determinada & 13 & 30,2 \\
\hline Não & 4 & 9,3 \\
\hline Total & 43 & 100 \\
\hline
\end{tabular}

Fonte: Dados da pesquisa (2019).

Finalmente, foi perguntado sobre a existência de uma política de gestão de riscos. Das universidades respondentes, 27 afirmaram que possuem essa política e que esta é formalizada, o representa $62,8 \%$. Por sua vez, 7 afirmaram que possuem política de gestão, mas que esta não se encontra formalizada, o que representa $16,3 \%$ das universidades. $\mathrm{E}$, como revela a Tabela 12, 9 universidades afirmaram não possuir uma política de gestão de riscos, o que representa $20,9 \%$.

Tabela 12 Existência de política de gestão de riscos

\begin{tabular}{l|c|c}
\hline & Frequência & Frequência relativa (\%) \\
\hline Sim, há uma política de gestão de riscos formalizada & 27 & 62,8 \\
\hline Sim, mas não se encontra formalizada & 7 & 16,3 \\
\hline Não & 9 & 20,9 \\
\hline Total & 43 & 100 \\
\hline
\end{tabular}

Fonte: Dados da pesquisa (2019). 
Nesse aspecto, é primordial destacar que 9 universidades não estão em acordo com o que estabelece o contido na lei $\mathrm{n}^{\mathrm{o}} 13.303 / 2016$,que versa sobre a obrigatoriedade de implementar e supervisionar práticas cotidianas dos sistemas de gestão de riscos e de controle interno estabelecidos para a prevenção e contenção dos principais riscos a que está exposta a entidades públicas, inclusive os riscos relacionados à integridade das informações contábeis e financeiras e os relacionados à ocorrência de corrupção e fraude. Isto claramente remete a problemas de conformidade.

\section{CONCLUSÃO}

Considerando que a importância que o controle interno possui na gestão das organizações, especificamente na gestão pública que tem na sociedade seu principal stakeholder, buscou-se investigar as características do controle interno nas Universidades Federais Brasileiras.

$\mathrm{Na}$ caracterização do perfil dos respondentes constatou-se uma predominância de respondentes do sexo masculino. Somado a isso se identificou que a maioria possuia graduação em ciências contábeis e que 40 dos 43 respondentes são pós-graduados. Além disso, $88,4 \%$ dos respondentes eram lotados na Auditoria interna.

$\mathrm{Na}$ investigação quanto às características do controle interno, de forma surpreendente sobre a universidade possuir em sua estrutura organizacional um órgão ou setor responsável pelo Controle Interno, 55,8\% das entidades afirmaram que não possuem. Como reflexo da não existência de órgão central responsável pelo controle interno, ficou evidenciado também uma pulverização de responsáveis pela elaboração dos controles internos nas instituições.

Foi observado ainda que no que diz respeito à importância atribuída ao controle interno, 90,7\% das universidades o consideram importante, em maior ou menor grau; e que a maioria realiza avaliações do sistema de controle interno da universidade, independente se o fazem com periodicidade determinada.

Diante do exposto, pode-se constatar que apesar da importância atribuída ao controle interno, pelas universidades pesquisadas, este ainda não encontra-se estabelecido de forma consolidada em todas as universidades. Ressalta-se que o controle interno assume uma importância no contexto da gestão das universidades, e como parte integrante de sua estrutura organizacional, por se tratar de uma ferramenta essencial na busca da transparência e evidenciação dos resultados e dos atos públicos, sendo importante ainda para assegurar o patrimônio público com vistas a garantir a eficiência na consecução do seu objetivo. 


\section{REFERÊNCIAS}

ALBUQUERQUE, J. M. Avaliação dos controles internos de uma instituição pública de ensino superior à luz da metodologia MCDA - construtivista. Revista Contemporânea de Contabilidade, v. 8 n.15, p. 129-150, 2011.

ARAÚJO, D. J. C.; LIBONATI, J. J.; MIRANDA, L. C.; RAMOS, F. S. Unidades de Controle Interno dos Municípios Brasileiros: Análise sob a Ótica do COSO II . Revista Universo Contábil, v.12, n.2, p. 39-58, 2016.

AYRES, L. C. N.; CRUZ, V. L.; SANTOS, R. R.; LEONE, R. J. G. Controle Interno em Empresas Familiares de Pequeno Porte: uma aplicação do modelo COSO II. Revista da Micro e Pequena Empresa, v.12, n. 1, p. 3-17, 2018.

BRASIL. Lei no 13.303, de 30 de Junho de 2016. Dispõe sobre o estatuto jurídico da empresa pública, da sociedade de economia mista e de suas subsidiárias, no âmbito da União, dos Estados, do Distrito Federal e dos Municípios. Disponível em: http://www.planalto.gov.br/ccivil 03/ ato2015-2018/2016/lei/113303.htm

CALIXTO, G. E.; VELAZQUEZ, M. D. P. Sistema de controle interno na administração pública federal. Revista Eletrônica de Contabilidade, v.2, n. 3, p. 63-81, 2005.

CASTRO, D. P. Auditoria, Contabilidade e controle interno no Setor Público. 3. ed. São Paulo: Atlas, 2010.

CHIARELLI, L.; CHEROBIM, A. P. M. S. Características de sistema de controle interno municipal para atuação reguladora e orientadora da gestão pública. Revista Interdisciplinar Científica Aplicada, v.3, n.1, p. 24-42, 2009.

CONTI, J. M.; CARVALHO, A.C. O Controle Interno na Administração Pública Brasileira: qualidade do gasto público e responsabilidade fiscal. Teorias e Estudos Científicos, v. 37, p. 201-220, 2011.

GIL, A. C. Como elaborar projetos de pesquisa. 4 ed. São Paulo: Atlas, 2002.

LORENZONI, R.; VIEIRA, E. T. V. V. O controle interno e a auditoria como ferramenta de desenvolvimento nas micro e pequenas empresas. Revista gestão e desenvolvimento em contexto- GEDECON, v. 1, n. 1, p. 118-132, 2013.

MAIA, M.S.; SILVA, M.R.; DUEÑAS, R.; ALMEIDA, P. P.; MARCONDES, S.; CHING, H.Y. Contribuição do sistema de Controle Interno para excelência Coorporativa. Revista Universo Contábil, v.1, n.1, p. 54-70, 2005.

MONTEIRO, R. P. Análise do sistema de controle interno no Brasil: objetivos, importância e barreiras para sua implantação. Revista Contemporânea de Contabilidade, v.12, n.25, p. 159-188, 2015. 
MORAES, M. A.; OLIVEIRA, A.G.; NIWA, T.H. Controle interno como instrumento de planejamento, organização transparência na administração pública município de Guarei/SP. Revista Controle - Doutrina e Artigos, v.11, n.2, p. 217-238, 2013.

OLIVEIRA, R. R. Contabilidade, Controle Interno e Controle Externo: Trinômio Necessário para Combater a Corrupção. Pensar Contábil, v. 8, n. 31, 2006.

OLIVEIRA, D. F. O controle interno e auditoria governamental: comparativo. Revista Controle Doutrina e Artigos, v.12, n.1, p. 196-210, 2014.

PEREIRA, N. P. Controles Internos Empresariais e Gestão: visões e importância - Uma Abordagem Exploratória. Contabilidade Vista \& Revista, v.15, n.10, p. 27-44, 2004.

PINTO, A. R. P. Avaliação do controle interno do departamento financeiro de uma empresa comercial - estudo de caso. Revista Eletrônica de Contabilidade, v. 3, n.1, p.124-150, 2006.

PRODANOV, C.C.; FREITAS, E.C. Metodologia do trabalho científico: métodos e técnicas da pesquisa e do trabalho acadêmico. 2 ed. Novo Hamburgo: Universidade Feevale, 2013.

QUEIROZ, M. A. S.; PETER. M. G. A.; MACHADO, M. V. V.; GOMES, A. O.; RODRIGUES, M. D. N. Controle interno e controladoria na Administração Pública: estudo nas universidades federais brasileiras. In: CONGRESSO BRASILEIRO DE CUSTOS, 19, 2012, Bento Gonçalves. Anais... Bento Gonçalves, 2012.

REZENDE, S. M.; FAVERO, H. L. A importância do Controle Interno dentro das organizações. Revista de Administração Nobel, v. 3, p. 33-44, 2004.

RITTA, C. O. Análise comparativa do controle interno nas contas a receber e a pagar nas empresas Beta Ltda. e Alfa Ltda. Revista Catarinense Da Ciência Contábil, v.9, n. 26, p. 63-78, 2010.

RODRIGUES, M. D. N. Controle interno e controladoria na Administração Pública: estudo nas universidades federais brasileiras. In: CONGRESSO BRASILEIRO DE CUSTOS, 19, 2012, Bento Gonçalves. Anais... Bento Gonçalves, 2012.

SANTOS, R. T.; MURARO, M. A influência da lei de responsabilidade fiscal nos Procedimentos de controle interno: uma análise nos Municípios gaúchos do Corede produção. In: CONGRESSO BRASILEIRO DE CONTABILIDADE, 18, 2008, Gramado. Anais... Gramado, 2008.

SILVA, P. G. K. O papel do controle interno na administração pública. Contexto, v. 2, n. 2, p. 1-16, 2002.

SOARES, M.; SCARPIN, J. E. Controle Interno na Administração Pública: avaliando sua eficiência na gestão municipal. UNOPAR Cient., Ciênc. Juríd. Empres., v.14, n.1, p. 5-15, 2013.

STEVENSON, W. J. Estatística Aplicada à Administração. Editora Harbra, 1981. 
THOMÉ, V. A.; TINOCO, J. E. P. A existência do Controle Interno como auxílio à governança para gerar informações aos stakeholders das entidades públicas: a realidade em 20 prefeituras do estado do Paraná-Brasil. In: CONGRESSO USP DE CONTROLADORIA E CONTABILIDADE, 5, 2005, São Paulo. Anais... São Paulo, 2005.

VASCONCELOS, T. C.; SAMPAIO, J. C. S.; SILVA NETO, A.F.; DUQUE, C. Funcionalidade do Controle Interno nos Municípios: Um Estudo nas Prefeituras de Uma Região Metropolitana do Nordeste. Advances in Scientific and Applied Accounting, v. 5, n.2, p. 201-221, 2012.

VIEIRA, E. R. F. C.; ARAÚJO, A. O.; GOMES, A. M.; GUIMARÃES, A. L. S.; ROCHA, M. M. Q. Controle interno dos estoques de medicamentos nos hospitais de Natal. Interface Revista do Centro de Ciências Sociais Aplicadas, v. 4, n. 2, p. 39-54, 2007.

WANG, J. J.; HOOPER, K. Internal control and accommodation in Chinese organisations. Critical Perspectives on Accounting, v. 49, p. 18-30, 2017. 